\title{
Cross-Strait climate change and agricultural product loss
}

\author{
Hsing-Chun Lin ${ }^{1} \cdot$ Li-Chen Chou $^{2} \cdot$ Wan-Hao Zhang ${ }^{3}$
}

Received: 6 December 2018 / Accepted: 11 April 2019 / Published online: 22 May 2019

(C) The Author(s) 2019

\begin{abstract}
The structure of agricultural industries at Cross-Strait differs as climate change is considered. In fact, its influence on their agriculture and other industries vary when the impact produced by natural disasters due to climate change are faced. To estimate direct and indirect losses caused by natural disasters, this study applies Inter-Country Input-Output (ICIO) analysis developed by Miller and Blair (2009) to discuss the development among Cross-Strait industries as they face disaster losses. The data sources used in this article are from Lin (2013), Cross-Strait ICIO table, and the statistics of agriculture in the periods 2005-2017 for Taiwan and Mainland China. The main results from our ICIO analysis are as follows: the value-added losses caused by natural disasters mainly involve agriculture, forestry, fishery, wholesale and retail trade, animal feed, and chemical fertilizer industries. These sectors account for $87.4 \%$ in Mainland China and $94.6 \%$ in Taiwan of total separately.
\end{abstract}

Keywords Climate change loss · Inter-Country Input-Output (ICIO) Model · Cross-Strait · Economic analysis

\section{Introduction}

Due to the impacts of warm and ocean currents, Taiwan's climate is influenced by continental and maritime weathers. Averagely, there are three or four typhoons during summer and autumn in Taiwan. Typhoons bring abundant rainfall spatially distributed in an unequal manner. Usually, such natural disasters trigger floods, landslides, and other losses. For instance, typhoon Morakot caused more than 600 fatal casualties and 164 billion losses in crops and infrastructures in 2009. Mainland China also suffered by natural disasters such as typhoon and droughts in recent years. Though total rainfall does not change too much year by year, its distribution varies

Responsible editor: Philippe Garrigues

Li-Chen Chou

zlc@wzbc.edu.cn

Wan-Hao Zhang

wanhao.zhang@kcl.ac.uk

1 Department of Applied Economics, National Chiayi University, Chiayi, Taiwan

2 Department of Economics, Wenzhou Business College, Wenzhou, China

3 School of Politics and Economics, King's College London, London, UK monthly. According to Office of State Flood Control and Drought Relief Headquarters, $43 \%$ of wheat fields were stricken by drought and 429 million people faced the problem of drinking water availability.

Climate change affects many fields in the environment, according to Ahmed et al. (2015), they found that 33\% of farmers in the study area within Punjab Province, Pakistan, were unwilling to pay for a planned climate change adaptation programme, whereas $67 \%$ were willing to pay (WTP) for the predominant reasons being 'impacts on agricultural production', 'feeling responsible for my contribution to climate change', and 'concern for the risk posed by climate change'. The study also found farmers who were more WTP for a climate change adaptation programme were more educated, had higher incomes, and had greater concern for climate change (Ahmed et al. 2015; McElhinney 2016). The general public's definition of natural disasters is relatively simple. As long as it is determined that disasters occurring in the surrounding natural environment will be defined as natural disasters. However, it is necessary to carefully analyse the intermediate occurrence process from the causes of disasters to the results of disasters. For the evaluation method, it is necessary to make changes and find corresponding definitions for the characteristics of the evaluation object (Mary and Pielke 2005). In other words, climate change not only affects the environment but also affects society awareness about the environment sustainability. 
Following the above, although Taiwan and Mainland China possess a different industrial structure, both suffer the consequences of natural disasters, including losses in agriculture and related industries. With the aim to evaluate direct and indirect impacts of natural disasters in agriculture between Taiwan and Mainland China, the supply-side Inter-Country Output analysis (Miller and Blair 2009) has been applied. To deal with, the Cross-Strait Inter-Country Input-Output table (Lin 2013) involving 96 sectors have been used (Appendix 1 ), which is actually the statistics of consequences of natural disasters in crops from the Council of Agriculture Statistics in Taiwan and Mainland China from 2005 to 2017.

The structure of this article is as follows. "Literature review" contains a literature review. In "Methodology", a discussion regarding the supply-side Inter-Country Input-Output analysis is carried out. "Empirical analysis" describes our empirical results, and finally, "Economic impact analysis" highlights the main conclusions in this paper.

\section{Literature review}

Agriculture is a high-impact and high-vulnerability industry. Whether it is a change in rainfall patterns or extreme weather events, it will have a serious impact on agricultural production. Therefore, in order to effectively develop agricultural adaptation strategies, the mastery of agricultural loss assessment under different rainfall intensities is important (Wang et al. 2014). In order to alleviate farmers' burden of natural disaster losses and stabilize agriculture and rural development, the relevant literatures on agricultural natural disasters or agricultural loss assessment in the past focus on agricultural disasters and their resulting safety concept with agricultural insurance (Claassen et al. 2011; Goodwin and Rejesus 2008). Some researchers also discussed the political economy of agricultural disaster relief allocation (Chang and Zilberman 2014; Garrett et al. 2006), and considered the government's role in agricultural disasters (Goodwin and Vado 2007).

To explore the impact derived from climate change in Agro-ecosystems, previous studies usually analyse the catastrophe risk, the losses caused by the disaster. For example, Rose et al. (1997) estimated the industrial impacts by earthquake with Regional Input-Output and linear programming. Gordon et al. $(1998,2004)$ estimated the transport damage by the earthquake simulation in south California and measured the direct and indirect costs of earthquake which integrated the Regional Input-Output model and the price model. Fischer et al. (2002) evaluated the development of economic system in the future via Basic Linked Systems (BLS) and Global Circulation Models (GCM). The study concluded that climate change influences all the natural ecosystems. In addition, it changes regional productivity and population growth in the long-term. Rose and Liao (2005) measured the related impacts with Computational General Equilibrium model for water supply system damage by earthquake. Yamano et al. (2007) explored the impacts on the regional industries which came from electricity and transport internet injuries caused by natural disasters in Japan; they found direct damages exceed indirect damages a lot and the impacts of manufacturing and commercial districts are worse than other areas.

Shi (2009) studied the crisis and response in a society after the natural disaster happened. Masud et al. (2017) indicated that socio-demographic factors such as gender, age, education, income, and ethnicity can greatly influence the individual's awareness, attitude, risk perception, and knowledge of climate change issues. Other studies like Krosnick et al. (2006), Lorenzoni and Pidgeon (2006), Leiserowitz (2006), and Zahran et al. (2006) have found that the influence of global warming will affect public's attention and the effects of climate change can also be influenced to a certain extent, by specific psychological and behavioural factors.

In the evaluation of climate change and economic growth, Furen et al. (2005) stated that climate change will affect population growth and economic development. As a consequence of rainfall decreasing, the risk of drought will rise and affect the productivity of related industries. They applied Social Accounting Matrix (SAM) and set up six situations to explore the economic impact during water restrictions. As a conclusion, food and beverage sectors will bear the worst losses in all the situations. Myles et al. (2005) evaluated the agricultural impacts of Katrina and Rita hurricanes in Mississippi. They discussed their impact on employment, commercial revenue, and labour income in short, middle, and long run. The results demonstrated that the impact of hurricanes have a significant influence in commercial revenue and labour income, even 15 years after the natural disaster occurred. Okuyama (2007) explored the advantages and disadvantages among Input-Output model, Computable General Equilibrium (CGE) model, and Social Accounting Matrix (SAM). The author noticed that a model to assess the economic impact is mainly focused on its accuracy. However, every disaster differs from others and may not exhibit the same degree of hazard. Tsuchiya et al. (2007) analysed the economic impacts of transportation system and infrastructure which faced Tokai-Tonankai earthquakes. The economic damage analysis based on Input-Output analysis and Computational General Equilibrium in the literature. The study expanded Computable General Equilibrium to Spatial Computable General Equilibrium (SCGE) and simulated the paralysis and overloading levels of transpose, internet structure.

Compared with the difference of methodology, Clower (2005) claimed the assessment of the economic impact of natural disasters is important. Analysis of disaster losses usually can be divided into macro-economic and micro-economic analysis. The former focused on a country or at least one of the state's gross domestic product impact assessments, the latter 
targeted the natural disaster losses which include the dynamic comparative of inter-temporal costs at different times.

Lin et al. (2010) combined the regional and supply side Input-Output analysis developed by Miller and Blair (2009) to evaluate the losses caused by natural disasters in agricultural productions of regional economies. They found that losses of agricultural productions provoked by natural disasters damaged income and employment, and the losses accounted for about $30 \%$ of Agriculture GDP. Charlotte (2003) measured the potential impact index of disasters by macro-economic side and concluded that the potential impact of disasters can be divided into the direct costs of physical losses, indirect costs of production losses, the second round or the overall affection in short run, and the losses of long-term effect such as government budget balance.

The main advantage of Regional Input-Output model is that both direct and indirect effects can be accounted. Other methodologies are econometric economic model and computable general equilibrium (CGE). The econometric economic model needs comprehensive data for simulation, whereas the computable general equilibrium results in being more complex than Regional Input-Output model. In this paper, we shall apply side InputOutput analysis to explore the impacts of natural disasters.

\section{Methodology}

IO, CGE, and other model methods are usually used in the literature for analysis, but the basic assumptions of these theories are different. Consider the degree of complementarity or substitution of bilateral trade in climate change for Taiwan and Mainland China, this paper applies the Inter-Country InputOutput model due to Miller and Blair (2009) to estimate the influence of agricultural product losses caused by climate change in Cross-Strait.

In the Inter-Country Input-Output table, total output can be represented in both middle and final demands, i.e.

$X=Z+F$

with $\mathrm{X}, \mathrm{Z}$, and $\mathrm{F}$ being output vector, middle demand matrix, and final demand. In addition, the multi-regional trade matrix is given by

$Z=\left[\begin{array}{ccc}Z_{i j}^{L L} & \cdots & Z_{i j}^{L K} \\ \vdots & \ddots & \vdots \\ Z_{i j}^{K L} & \cdots & Z_{i j}^{K K}\end{array}\right]$

where $Z_{i j}^{L L}$ is the $i$ th commodity produced in the $j$ th industry located at the $L$ th region. $Z_{i j}^{L K}$ denotes the outputs at the $K$ th region derived from the $j$ th industry and its inputs produced in the $L$ th region. $Z_{i j}^{K L}$ and $Z_{i j}^{K K}$ are defined similarly to $Z_{i j}^{L L}$ and $Z_{i j}^{L K}$, resp. The regional outputs are described below:

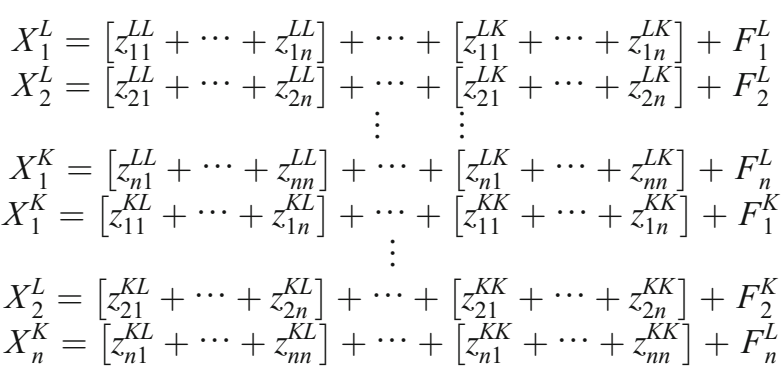

If the input coefficients are fixed and the relationships of input and output are regulated, the coefficient of middle input in different regions is provided by the following expression:

$$
\begin{aligned}
& A=\left[\begin{array}{ccc}
A^{L L} & \cdots & A^{L K} \\
\vdots & \ddots & \vdots \\
A^{K L} & \cdots & A^{K K}
\end{array}\right]
\end{aligned}
$$

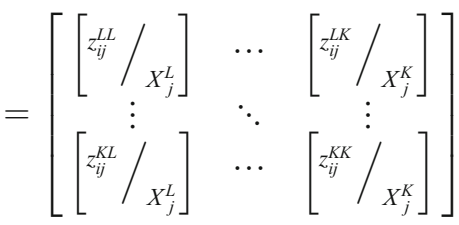

We also define the total output matrix, $X$, and the final demand matrix, $F$, in the following terms:

$X=\left[\begin{array}{c}X^{L} \\ \vdots \\ X^{K}\end{array}\right] F=\left[\begin{array}{c}F^{L} \\ \vdots \\ F^{K}\end{array}\right]$

The equation of balance between supply and demand is given by

$X=A X+F$

Hence,

$(I-A) X=F$

with $(I-A)$ being the Leontief matrix. Thus, $X$ can be solved whenever such a matrix is non-singular. In fact,

$X=(I-A)^{-1} F$

In Eq. (7), $(I-A)^{-1}$ is the matrix of direct and indirect requirements, also called as matrix of inter-industry interdependence coefficients or Leontief inverse matrix. Equation (7) explains the new equilibrium outputs as the final demand changes by

$\Delta X=(I-A)^{-1} \Delta F$

The Input-Output table allows classifying sections such as domestic and imported goods. Thus, the final demand can be decomposed into domestic part $(Z d)$ and other part $(Z m)$ to explore the dependence among different industries in the process of international trade: 


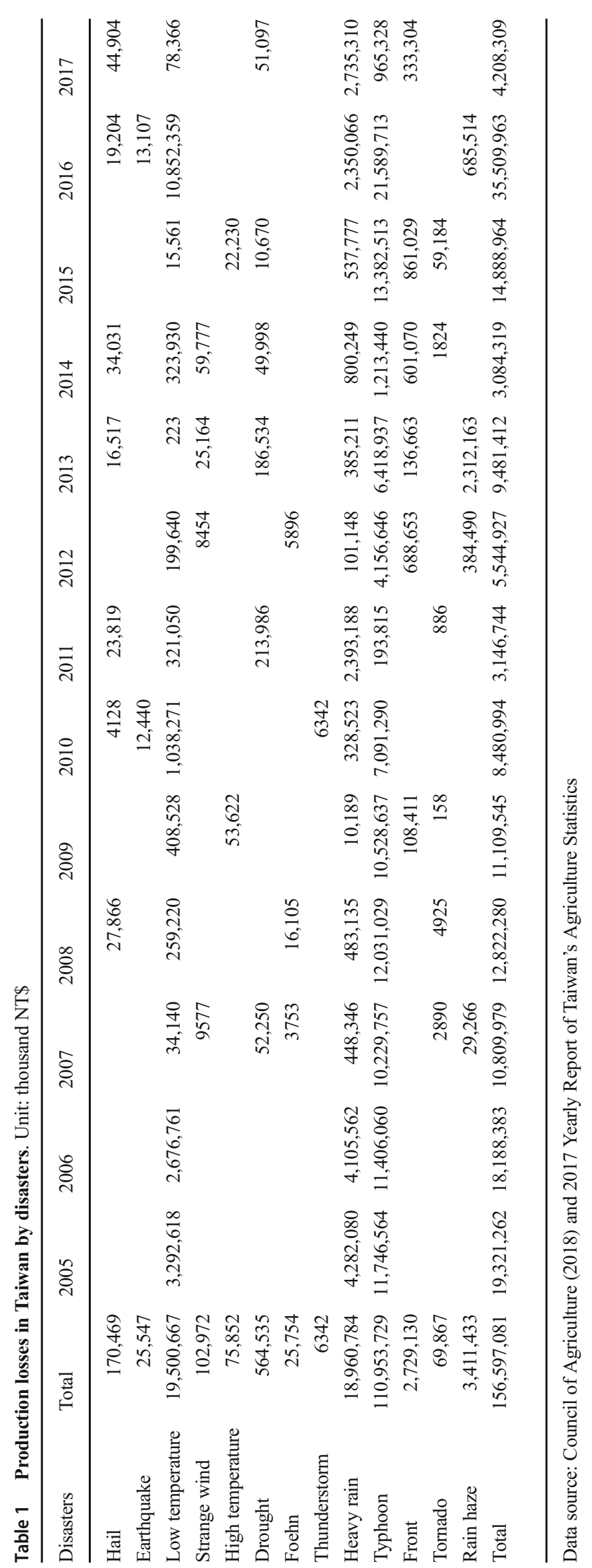


$Z=\left[\begin{array}{ccc}{\left[Z d i_{i j}^{L L}+Z m_{i j}^{L L}\right]} & \cdots & {\left[Z d_{i j}^{L K}+Z m_{i j}^{L K}\right]} \\ \vdots & \ddots & \vdots \\ {\left[Z d_{i j}^{K L}+Z m_{i j}^{K L}\right]} & \cdots & {\left[Z d_{i j}^{K K}+Z m_{i j}^{K K}\right]}\end{array}\right]=Z^{D}+Z^{M}$

$F=\left[\begin{array}{c}{\left[F d_{i j}^{L}+F m_{i j}^{L}\right.} \\ \vdots \\ {\left[F d_{i j}^{K}+F m_{i j}^{K}\right]}\end{array}\right]=\left[\begin{array}{c}{\left[F d_{i j}^{L}\right]} \\ \vdots \\ {\left[F d_{i j}^{K}\right]}\end{array}\right]+\left[\begin{array}{c}{\left[F m_{i j}^{L}\right]} \\ \vdots \\ {\left[F m_{i j}^{K}\right]}\end{array}\right]=F^{D}+F^{M}$

Hence, Eq. (4) can be rewritten as follows:

$A=\left[\begin{array}{ccc}{\left[Z d_{i j}^{L L}+Z m_{i j}^{L L} / X_{j}^{L}\right]} & \cdots & {\left[Z d_{i j}^{L K}+Z m_{i j}^{L K} / X_{j}^{K}\right.}\end{array}\right]$.

If both Eqs. (9) and (10) are substituted in Eq. (5), it holds that

$X=A^{D} X+F^{D}$

$A^{D}=\left[\begin{array}{ccc}{\left[Z d_{i j}^{L L} / X_{j}^{L}\right]} & \cdots & {\left[Z d_{i j}^{L K} / X_{j}^{K}\right.} \\ \vdots & \ddots & \vdots \\ {\left[Z d_{i j}^{K L} / X_{j}^{L}\right]} & \cdots & {\left[Z d_{i j}^{K K} / X_{j}^{K}\right.}\end{array}\right] \cdot F^{D}=\left[\begin{array}{c}{\left[F d_{i j}^{L}\right]} \\ \vdots \\ {\left[F d_{i j}^{K}\right]}\end{array}\right]$

As such, the Leontief matrix can be solved in domestic goods by

$\left(I-A^{D}\right) X=F^{D}$

Let us determine $X$ as well as the equation that analyses the changes of final demand:

$X=\left(I-A^{D}\right)^{-1} F^{D}$

$\Delta X=\left(I-A^{\mathrm{D}}\right)^{-1} \Delta F^{\mathrm{D}}$

The output effect in Eq. (15) can be transformed into the value-added effect:

$\Delta V=v\left(I-A^{\mathrm{D}}\right)^{-1} \Delta F^{\mathrm{D}}$

From Eq. (7), both $X=(I-A)^{-1} F$ and the inverse of the Leontief matrix, $(I-A)^{-1}$, are known. Denote $B=(I-A)^{-1}$ with elements named as $b_{i j}$. Thus, we can write

$B=(I-A)^{-1}=\left|\begin{array}{c}b_{11} b_{12} \cdots b_{1 i} b_{1 j} \cdots b_{1 n} \\ b_{21} b_{22} \cdots b_{2 i} b_{2 j} \cdots b_{2 n} \\ \vdots \\ b_{i 1} b_{i 2} \cdots b_{i i} b_{i j} \cdots b_{i n} \\ b_{j 1} b_{j 2} \cdots b_{j i} b_{j j} \cdots b_{j n} \\ \vdots \\ b_{n 1} b_{n 2} \cdots b_{n i} b_{n j} \cdots b_{n n}\end{array}\right|$
Notice that $b_{i j}$ is the final demand-to-output multiplier with

$b_{j j}=\frac{\Delta X_{i}}{\Delta F_{j}}$.

Let $b_{i j}^{*}$ be the ratio between $b_{i j}$ and $b_{j j}$, i.e.

$b_{i j}^{*}=\frac{b_{i j}}{b_{j j}}$

Next, let us substitute Eq. (19) into Eq. (17):

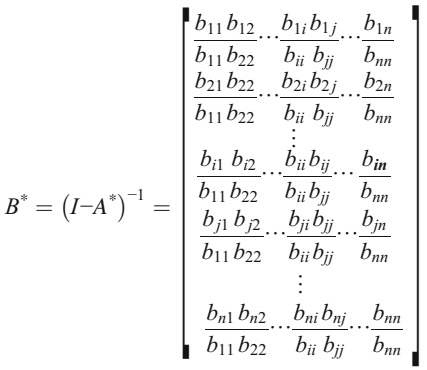

or equivalently,

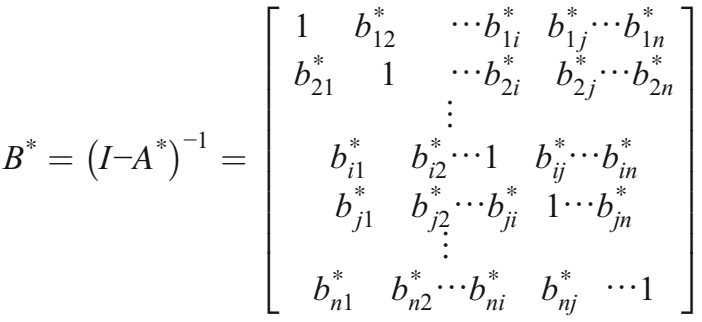

Similarly, the total output effect under different situations such as final demand changes, domestic goods, output effect,

Table 2 Production losses in Taiwan's agriculture by products. Unit: thousand NT\$

\begin{tabular}{rrrrrr}
\hline Year & Total & Agriculture & Livestock & \multicolumn{1}{l}{ Fishery } & \multicolumn{1}{l}{ Forest } \\
\hline 2005 & $20,476,776$ & $18,000,771$ & 364,190 & $1,857,258$ & 254,557 \\
2006 & $3,250,295$ & $3,137,993$ & 27,734 & 73,100 & 11,468 \\
2007 & $11,069,356$ & $10,637,125$ & 104,869 & 281,278 & 46,084 \\
2008 & $13,419,717$ & $12,559,055$ & 117,984 & 719,862 & 22,816 \\
2009 & $20,527,517$ & $10,893,704$ & $1,556,337$ & $4,969,907$ & $3,107,569$ \\
2010 & $9,114,662$ & $8,069,760$ & 192,430 & 817,612 & 34,860 \\
2011 & $3,424,159$ & $3,146,149$ & 3171 & 269,381 & 5458 \\
2012 & $5,750,631$ & $5,545,099$ & 17,667 & 142,941 & 44,924 \\
2013 & $9,699,921$ & $9,481,411$ & 82,764 & 97,934 & 37,812 \\
2014 & $3,124,563$ & $3,084,320$ & 4801 & 20,847 & 14,595 \\
2015 & $16,050,399$ & $14,432,167$ & 25,969 & 246,936 & 60,093 \\
2016 & $38,339,665$ & $27,283,608$ & 79,367 & $6,738,245$ & $1,408,743$ \\
2017 & $4,313,482$ & $3,973,372$ & 24,234 & 188,660 & 5284 \\
\hline
\end{tabular}

The same data source as in Table 1 
Table 3 Area affected by natural disasters in Mainland China. Unit: thousand hectares

\begin{tabular}{lrrrrrrrrrrrrr}
\hline Disaster & 2005 & 2006 & 2007 & \multicolumn{1}{c}{2008} & 2009 & 2010 & 2011 & 2012 & 2013 & 2014 & 2015 & 2016 & 2017 \\
\hline Drought & 16,028 & 20,738 & 29,386 & 12,137 & 29,259 & 13,259 & 16,304 & 9340 & 14,100 & 12,272 & 10,610 & 9873 & 9,875 \\
Flood disaster & 10,932 & 8003 & 10,463 & 6477 & 7613 & 17,525 & 6863 & 7730 & 8760 & 4718 & 5620 & 8531 & 5,415 \\
Wind hail & 2977 & 4387 & 2986 & 4180 & 5493 & 2180 & 3309 & 2781 & 3387 & 3225 & 2918 & 2908 & 2,268 \\
Low temperature & 4428 & 4913 & 4072 & 14,696 & 3673 & 4121 & 4447 & 1618 & 2320 & 2133 & 900 & 2885 & 525 \\
and freezing & & & & & & & & & & & & \\
Typhoon & 4453 & 2952 & 2086 & 2310 & 1146 & 342 & 0 & 0 & 0 & 0 & 0 & 0 & 0 \\
Total & 38,818 & 40,993 & 48,993 & 39,800 & 47,184 & 37,427 & 30,923 & 21,469 & 28,567 & 22,348 & 20,048 & 24,197 & 18,083 \\
\hline
\end{tabular}

Data source: Ministry of Agriculture, People's Republic of Mainland China, http://www.agri.gov.cn

and the value-added effect can be calculated throughout the following expressions:

$$
\begin{aligned}
& \Delta X=\left(I-A^{*}\right)^{-1} \Delta \bar{X}, \\
& \Delta X=\left(I-A^{D^{*}}\right)^{-1} \Delta \bar{X},
\end{aligned}
$$

and

$$
\Delta V=v\left(I-A^{D^{*}}\right)^{-1} \Delta \bar{X}
$$

\section{Empirical analysis}

In this article, we use an Input-Output table between Taiwan and Mainland China in 2006 and 2011 involving 96 sectors (Lin 2013). Agriculture losses refer not only those from production but also from equipment. This study is focused on the production losses. Tables 1, 2, 3, and 4 display Taiwan's losses in the periods 2005-2017 and Taiwan's losses in the periods 2005-2017, resp. Table 1 highlights the increasing of losses year by year in Taiwan. The worst losses occurred in 2016, which caused a drawdown in supplies to several industries relying on agricultural inputs. The total losses in Taiwan from 2005 to 2017 amount to 156.6 billion. Table 1 also shows that losses caused by typhoon and heavy rain account for 83\% (129.9 billion). As such, these two natural disasters caused a great impact in agriculture.

Table 3 exhibits the area affected by natural disasters in Mainland China from 2005 to 2017. Notice that the area affected increases year by year, with drought being the worst disaster in Mainland China. If the affected areas are divided by total arable lands, the amount of losses each year can be calculated. In this way, Table 4 states that the economic losses vary from 114.5 to 192.3 billion each year.

Table 4 Amount of losses in China by disaster. Unit: thousand hectares, \%, 100 million RMB

\begin{tabular}{lrrrrrrrrrrrrrr}
\hline Year & 2005 & 2006 & 2007 & 2008 & 2009 & 2010 & 2011 & 2012 & 2013 & 2014 & 2015 & 2016 & 2017 \\
\hline Affected area & 38,818 & 40,993 & 48,993 & 39,800 & 47,184 & 37,427 & 30,923 & 21,469 & 28,567 & 22,348 & 20,048 & 24,197 & 18,083 \\
Arable land & 130,039 & 130,039 & 121,735 & 121,716 & 121,716 & 121,716 & 121,716 & 135,158 & 135,163 & 135,057 & 134,999 & 134,921 & 134,881 \\
Ratio of disaster & 29.85 & 31.52 & 40.25 & 32.7 & 38.77 & 30.75 & 25.41 & 15.88 & 21.14 & 16.55 & 14.85 & 17.93 & 13.41 \\
$\quad$ affection & & & & & & & & & & & & \\
Production & & & & & & & & & & & \\
$\quad$ Agriculture & 19,613 & 21,522 & 24,658 & 28,044 & 30,778 & 36,941 & 41,989 & 46,941 & 51,497 & 54,772 & 57,636 & 59,288 & 61,720 \\
Livestock & 13,311 & 12,084 & 16,125 & 20,584 & 19,468 & 20,826 & 25,771 & 27,189 & 28,436 & 28,956 & 29,780 & 31,703 & 30,285 \\
Forest & 1426 & 1611 & 1862 & 2153 & 2193 & 2595 & 3121 & 3447 & 3902 & 4256 & 4436 & 4632 & 4992 \\
Fishery & 4016 & 3971 & 4458 & 5203 & 5626 & 6422 & 7568 & 8706 & 9635 & 10,334 & 10,881 & 11,603 & 12,317 \\
Loss & & & & & & & & & & & & \\
$\quad$ Agriculture & 5855 & 6785 & 9924 & 9170 & 11,931 & 11,359 & 10,668 & 7456 & 10,884 & 9063 & 8559 & 10,633 & 8275 \\
$\quad$ Livestock & 3973 & 3809 & 6490 & 6731 & 7547 & 6404 & 6547 & 4319 & 6010 & 4791 & 4422 & 5686 & 4060 \\
Forest & 426 & 508 & 749 & 704 & 850 & 798 & 793 & 548 & 825 & 704 & 659 & 831 & 669 \\
Fishery & 1199 & 1252 & 1794 & 1701 & 2181 & 1975 & 1923 & 1383 & 2036 & 1710 & 1616 & 2081 & 1651 \\
\hline
\end{tabular}

The same data source as in Table 4 


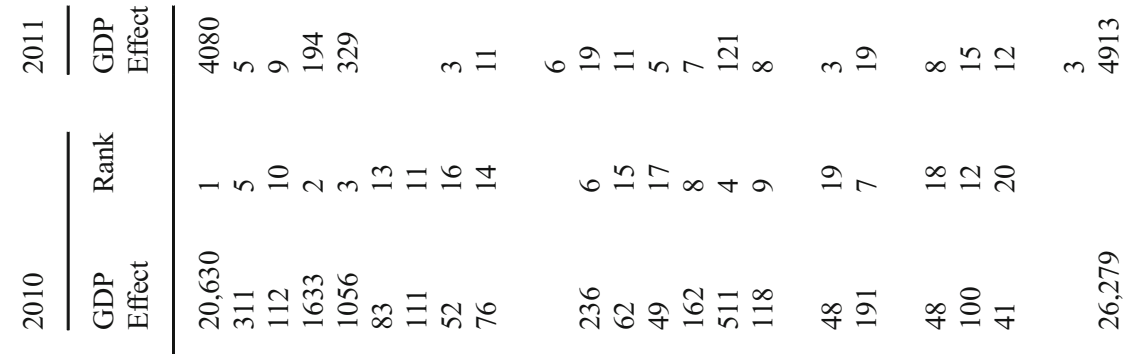
兹

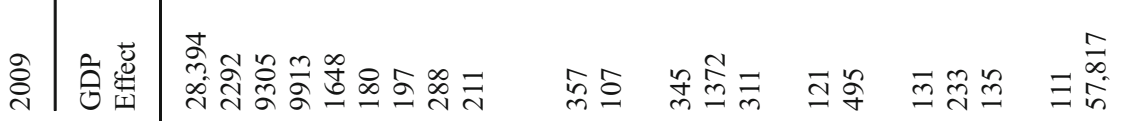

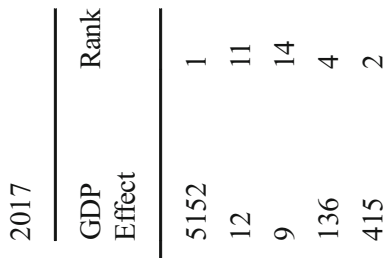

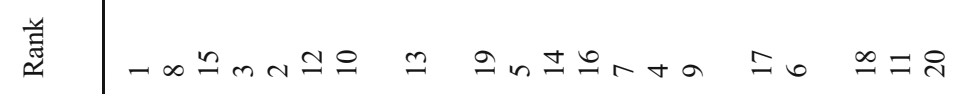

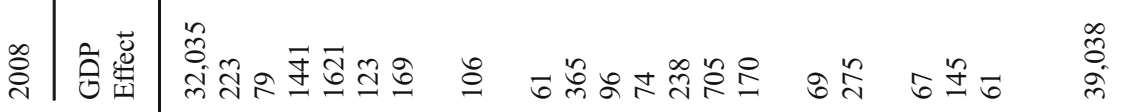

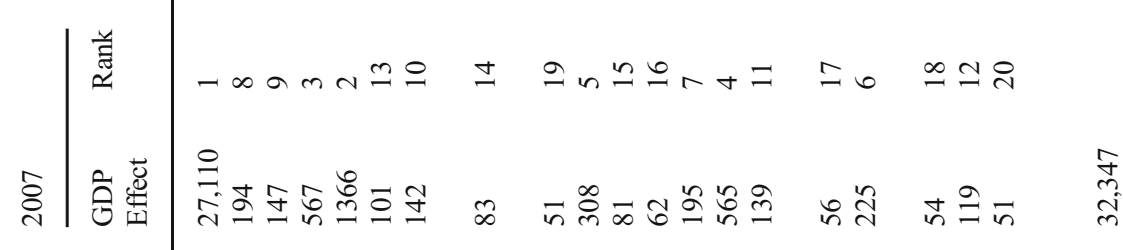

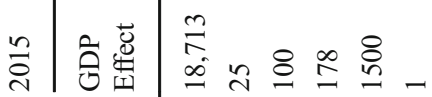

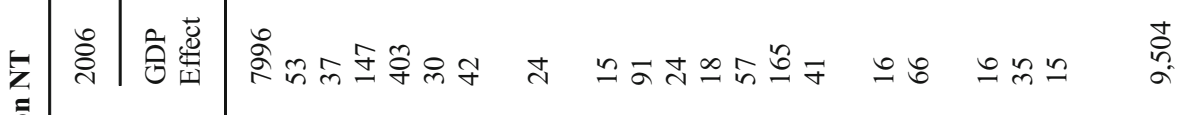

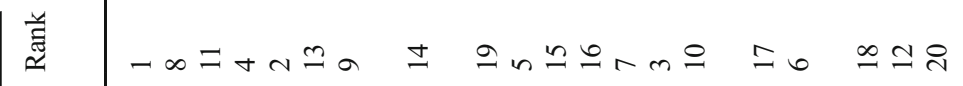

in

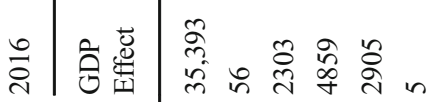

羌 $-\stackrel{0}{a} n+d \stackrel{\infty}{\circ}$

ता

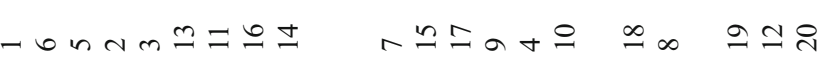

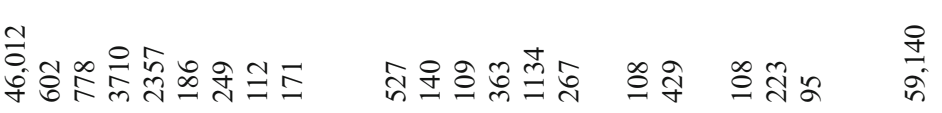

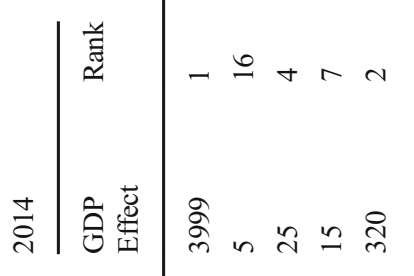

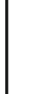

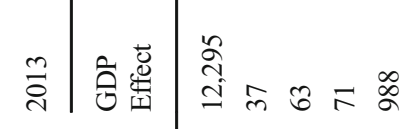

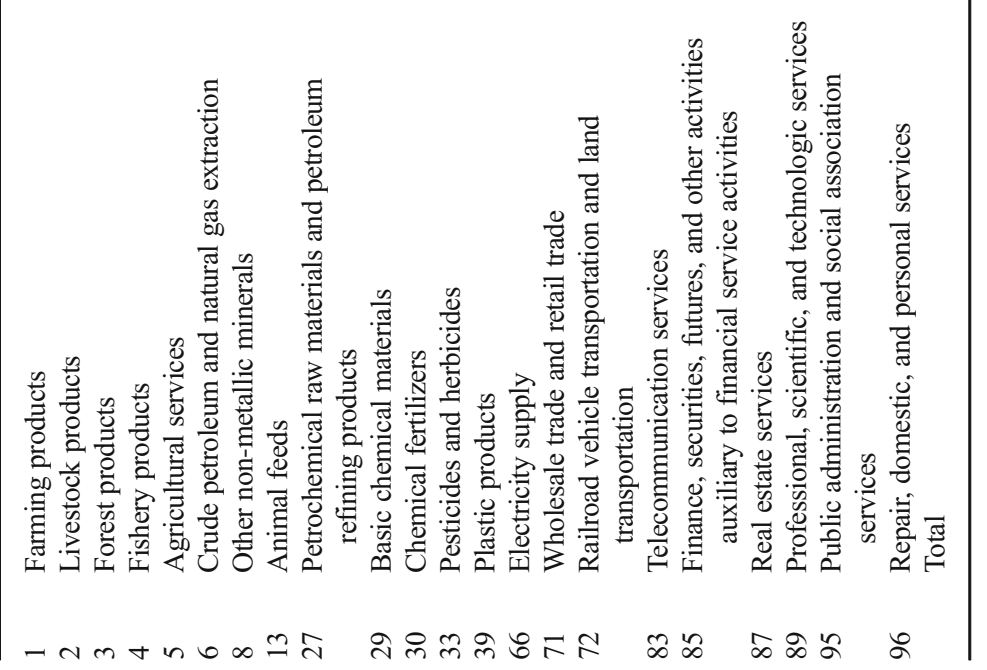

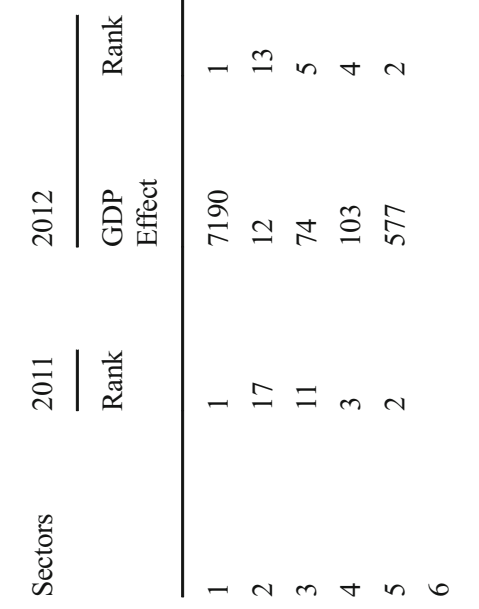




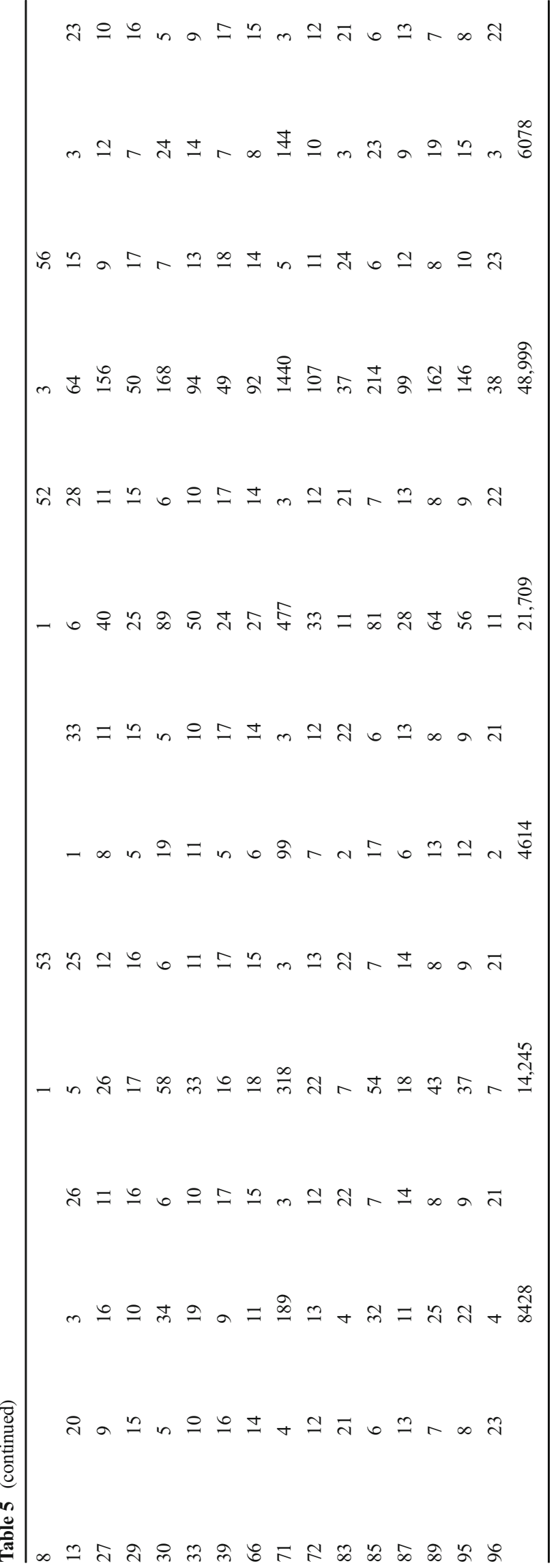

\section{Economic impact analysis}

Supply-side Inter-Country Input-Output analysis is applied to assess the impact caused by natural disasters in both Taiwan and China's economic systems. Losses were estimated in value-added effects. Table 5 provides the value-added losses provoked by natural disasters in Taiwan in the periods 2005-2017. Those effects range from 6 billion to 39 billion NT. The worst reduction was found in agriculture accounting for $94.6 \%$ of total losses, followed by wholesale and retail trade industries. The last place corresponds to chemical fertilizer industry.

Following the above, wholesale and retail industries appear in second place with an input coefficient equal to 0.07 units in agricultural production offer. Since the forward linkage of wholesale and retail is bigger, the economic effect of that industry accounts for $0.5 \%$ averagely.

The thirdly ranked flow coefficient corresponds to chemical fertilizers with 0.10 units in agricultural production offer. A large backward linkage with agriculture leads to production losses as well as losses in value-added effects of chemical fertilizers industry.

Table 6 displays the value-added losses by natural disasters in Mainland China from 2005 to 2017. The range of effect lies between 1965.6 to 5935.4 billion RMB. Agriculture accounts the largest effect by $87.4 \%$ in 2017 , followed by wholesale and retail trade, and animal feed.

Agriculture has the greatest impact by natural disasters. An input coefficient of agriculture equal to 1.14 means that losses will bring damage forward linkage. It holds that losses of productions and value-added in agriculture account for more than $65 \%$ jointly.

Agriculture, wholesale and retail trade, animal feed, and chemical fertilizer industries present the highest impacts between Taiwan and Mainland China. Comparing both Taiwan's and China's multipliers, we found that the Chinese one (2.6) stands larger than Taiwan's (2.9). This result highlights that Taiwan's losses are larger than Chinese ones whenever the same natural disasters are faced in Cross-Strait.

\section{Conclusions}

To estimate direct and indirect losses caused by natural disasters, this study applies Inter-Country Input-Output (ICIO) analysis developed by Miller and Blair (2009) to discuss the development among Cross-Strait industries as they face disaster losses. In this study, we applied Supply-side Inter-Country Input-Output analysis with the aim to assess the impact of climate change in Taiwan and China's economic systems. Our main results are stated below:

- The value-added losses caused by natural disasters mainly involve agriculture, forestry, fishery, wholesale and retail 


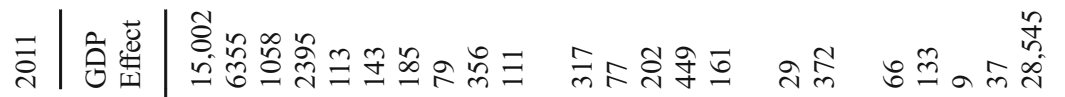

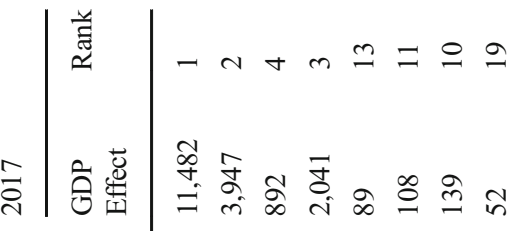

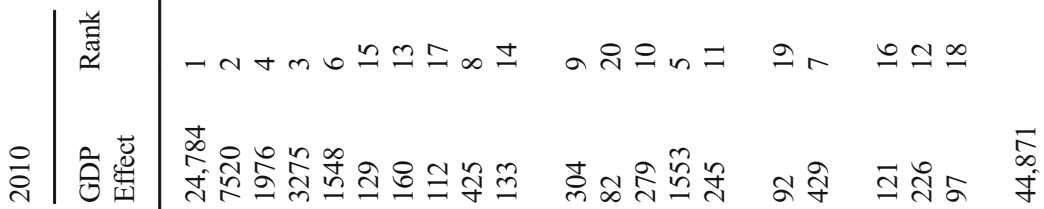

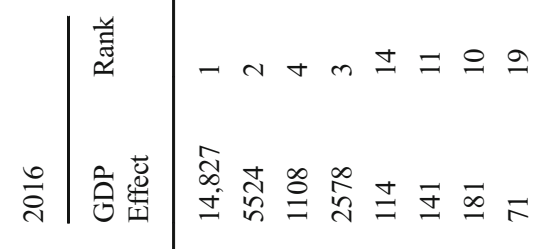

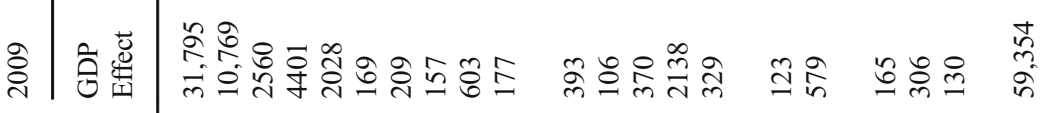

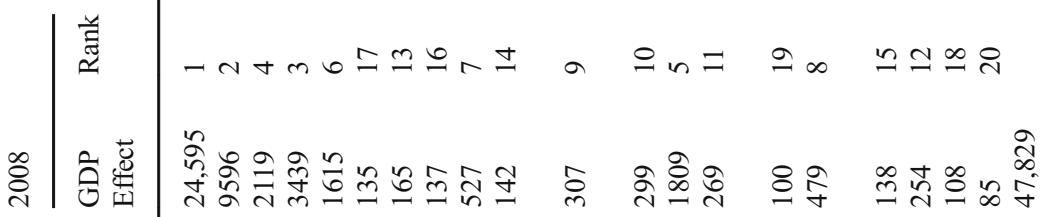

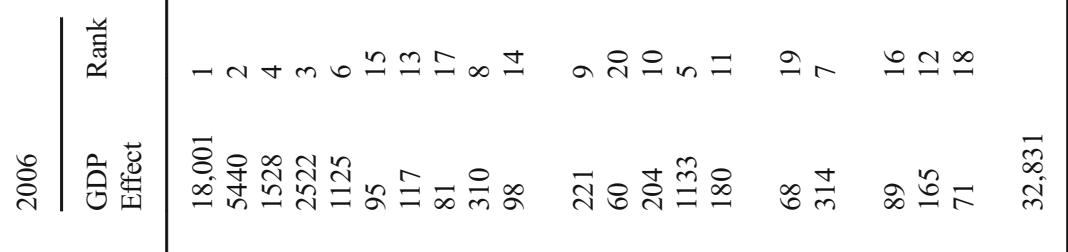

突

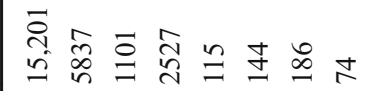

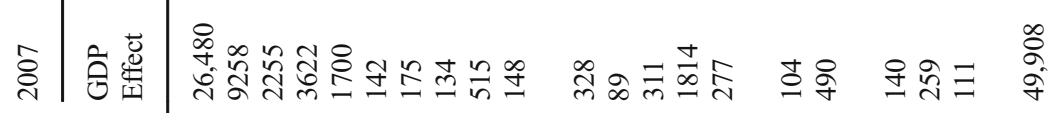

突

तु

올

䮍

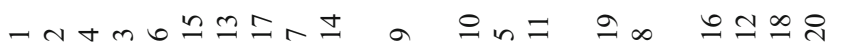

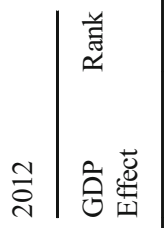

$-n+m \pm \Xi=9$

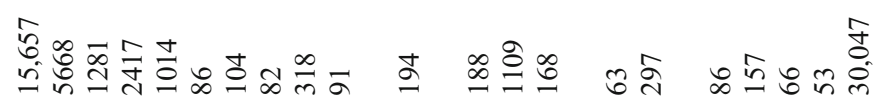

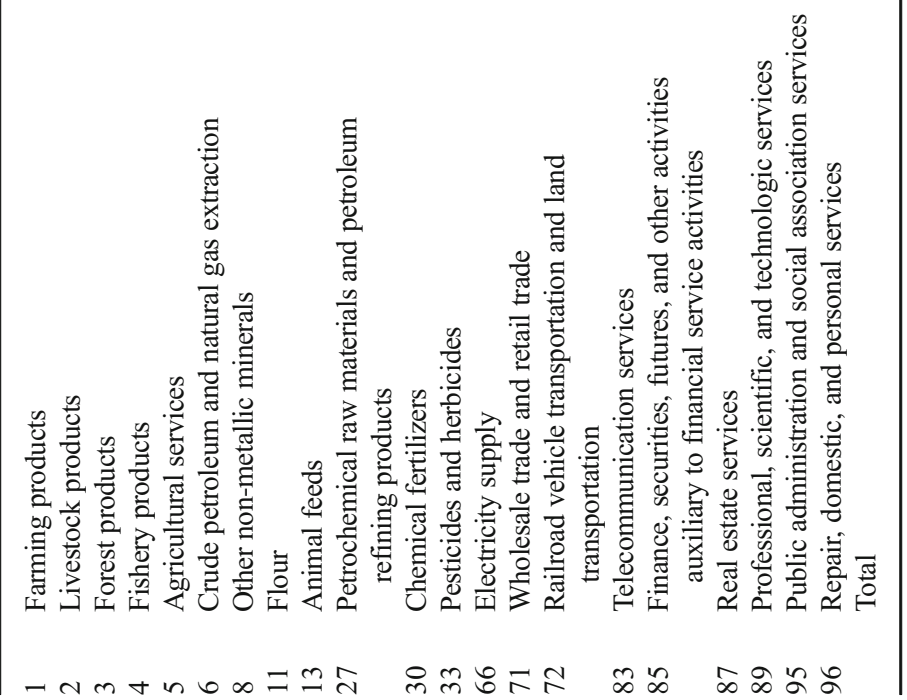

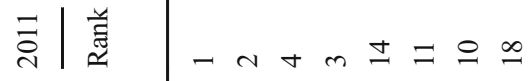

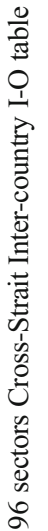

孚誉 


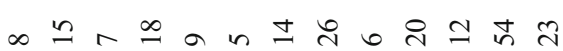

$$
\begin{aligned}
& \text { तั }
\end{aligned}
$$

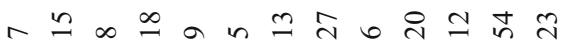

$$
\begin{aligned}
& \text { ๗ิ) }
\end{aligned}
$$

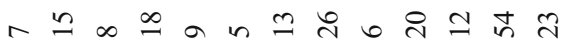

$$
\begin{aligned}
& \text { ฟิ }
\end{aligned}
$$

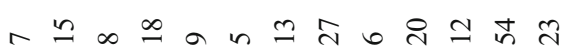$$
\text { तส }
$$

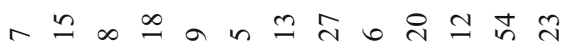

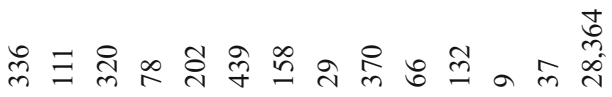

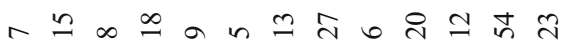

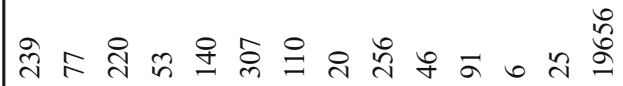

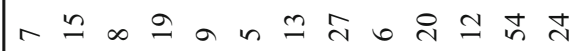

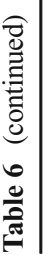

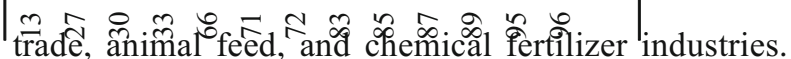

\section{Appendix. The compiling explanation of 96 sectors Cross-Strait ICIO table}

National Input-Output tables are able to track domestic value-added flows as they pass through the producers of a given economy, but they are not able to identify where the value-added in imports originated. To fully account for value-added flows therefore, and to construct measures of trade in value-added, an InterCountry Input-Output (ICIO) table is needed.

ICIO tables are the underpinnings of trade measuring in value-added. There is a consensus among international statistical agencies that direct measuring of trade in value-added is extremely difficult. The most feasible and promising approach to develop comprehensive and consistent measure for trade in value-added that goes beyond case studies of individual products (such as the iPod) has to use ICIO tables. With a growing recognition of the need to have a comprehensive global I-O table in order to measure trade in value-added properly and timely, four ICIO databases have been developed. The most widely known ICIO databases being used to discuss economic and trade issue are The World Input-Output (WIOD) database, GTAP database, The OECD ICIO database, and IDE-JETRO Asia International Input-Output tables. The common problem for these ICIO databases is that the classification of sectors is too aggregated. Therefore, in this study, apply Lin (2013) compile the 96 sectors Cross-Strait Inter-country Input Output (ICIO) table in 2006. 
Table 7 The sector classification of 96 Sectors Cross-Strait International Input-Output Table in 2006

\begin{tabular}{|c|c|c|c|}
\hline No. & Sectors & No. & Sectors \\
\hline 001 & Farming products & 049 & Audio and video electronic products \\
\hline 002 & Livestock products & 050 & Other electronic equipment and unrecorded data storage media \\
\hline 003 & Forest products & 051 & Precision instruments and apparatus \\
\hline 004 & Fishery products & 052 & Power generation, transmission, and distribution machinery \\
\hline 005 & Agricultural services & 053 & Wires, cables, and wiring devices \\
\hline 006 & Crude petroleum and natural gas extraction & 054 & Domestic appliances \\
\hline 007 & Metallic minerals & 055 & Other electrical materials \\
\hline 008 & Other non-metallic minerals & 056 & Metal processing machinery \\
\hline 009 & Slaughtering and by-products & 057 & Other special-purpose machinery \\
\hline 010 & Edible oil \& fat by-products & 058 & Boilers and pressure containers \\
\hline 011 & Flour & 059 & $\begin{array}{l}\text { General-purpose machinery, repair, and installation of industrial machinery } \\
\text { and equipment }\end{array}$ \\
\hline 012 & Sugar & 060 & Motor vehicles \\
\hline 013 & Animal feeds & 061 & Ships \\
\hline 014 & Seasonings & 062 & Other transport equipment \\
\hline 015 & Seasonings & 063 & Furniture \\
\hline 016 & Other foods & 064 & Education and entertainment articles \\
\hline 017 & Alcoholic beverages & 065 & Other manufactures \\
\hline 018 & Non-alcoholic beverages & 066 & Electricity supply \\
\hline 019 & Tobacco & 067 & Gas supply \\
\hline 020 & Fibre products & 068 & City water and remediation services \\
\hline 021 & Wearing apparel and clothing accessories & 069 & Construction \\
\hline 022 & Leather and other leather products & 070 & Wholesale trade and retail trade \\
\hline 023 & Wood products & 071 & Railroad vehicle transportation and land transportation \\
\hline 024 & Pulp, paper, and paper products & 072 & Water transportation \\
\hline 025 & Printing and reproduction of recorded media & 073 & Air transportation \\
\hline 026 & $\begin{array}{l}\text { Petrochemical raw materials and petroleum refining } \\
\text { products }\end{array}$ & 074 & Other transportation and supporting services to transportation \\
\hline 027 & Coke and other coal products & 075 & Warehousing and storage \\
\hline 028 & Basic chemical materials & 076 & Postal and courier services \\
\hline 029 & Chemical fertilizers & 083 & $\begin{array}{l}\text { Finance, securities, futures and other activities auxiliary to financial service } \\
\text { activities }\end{array}$ \\
\hline 030 & Compound fertilizers & 084 & Insurance \\
\hline 031 & Chemical fibres & 085 & Real estate services \\
\hline 032 & Pesticides and herbicides & 077 & Accommodation services \\
\hline 033 & Coatings, dyes, and pigments & 078 & Food and beverage services \\
\hline 034 & Cleaning preparations and cosmetics & 079 & News and publishing \\
\hline 035 & Other chemical products & 080 & Communication services \\
\hline 036 & Medicines & 081 & Telecommunication services \\
\hline 037 & Rubber products & 082 & Information services \\
\hline 038 & Plastic products & 086 & Research and development services \\
\hline 039 & Glass and glass products & 087 & Professional, scientific, and technologic services \\
\hline 040 & Ceramic products & 088 & Renting and leasing services \\
\hline 041 & Cement and other non-metallic mineral products & 089 & Travel agency services \\
\hline 042 & Pig iron and crude steel & 090 & Public facilities, buildings, and greenery services \\
\hline 043 & Primary iron and steel products & 091 & Educational services \\
\hline 044 & Other metals & 092 & Medical, health, and social services \\
\hline 045 & Fabricated metal products & 093 & Arts, entertainment, and recreation services \\
\hline 046 & Electronic components and parts & 094 & Public administration and social association services \\
\hline 047 & $\begin{array}{l}\text { Computer products and computer peripheral } \\
\text { equipment }\end{array}$ & 095 & Repair, domestic, and personal services \\
\hline 048 & Communication equipment & 096 & Undistributed and waste \\
\hline
\end{tabular}


Table 8 Framework of Cross-Strait Inter-country Input Output Table

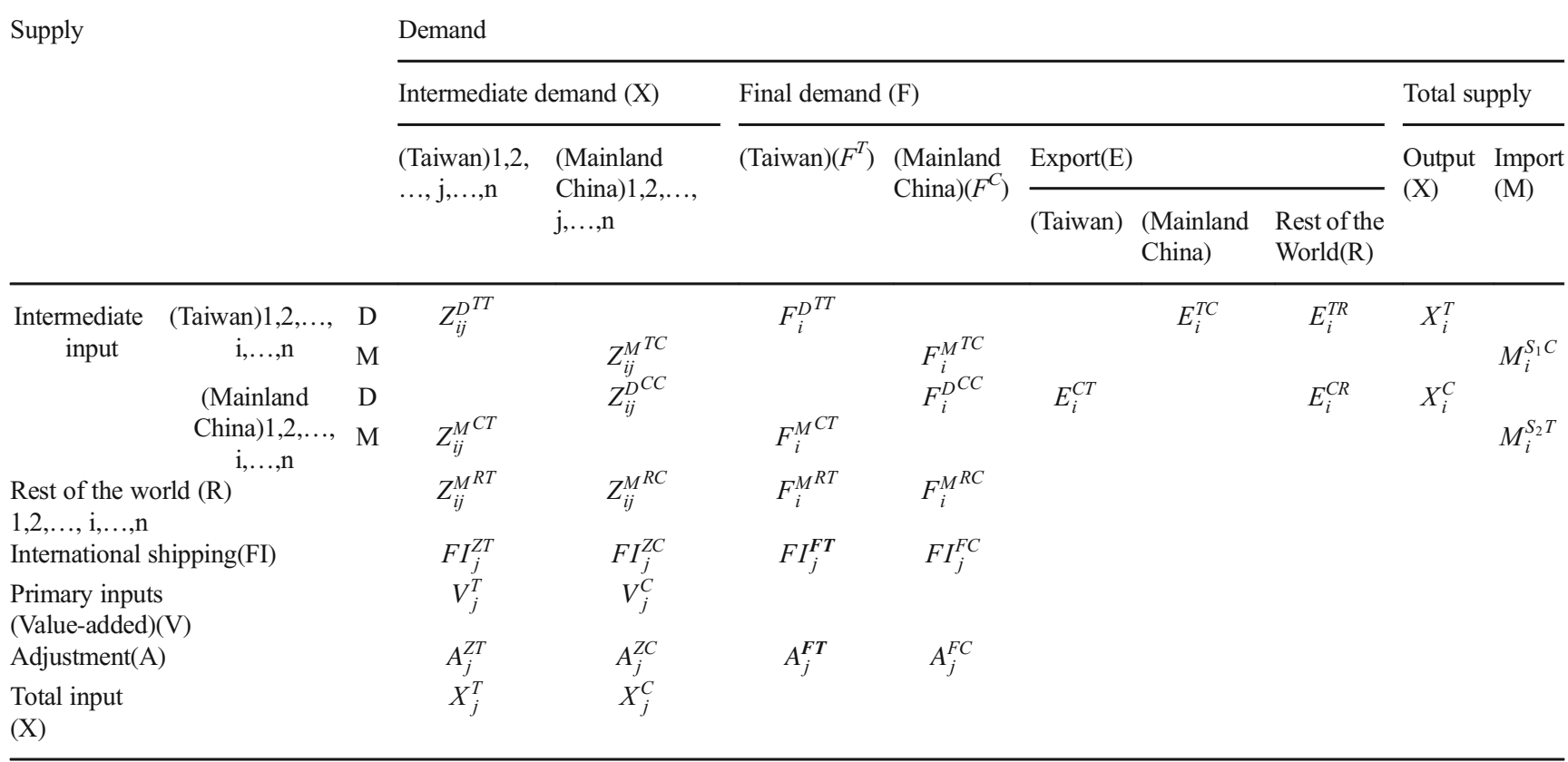

Source:Lin (2013)

$Z_{i j}^{D^{T T}}$ :the $j$ th industry of Taiwan $(\mathrm{T})$ uses the $i$ th's domestic products or service of Taiwan $(\mathrm{T})$ as intermediate input

$Z_{i j}^{M^{T C}}$ :the $j$ th industry of Mainland China (C) uses the imported products or service from the $i$ th's industry in Taiwan (T) as intermediate input

$Z_{i j}^{D C C}$ :the $j$ th industry of Mainland China $(\mathrm{C})$ uses the $i$ th's domestic products or service of Mainland China (C) as intermediate input

$Z_{i j}^{M C T}$ :the $j$ th industry of Taiwan (T) uses the $i$ th's import products or service of Mainland China $(\mathrm{C})$ as intermediate input

$Z_{i j}^{M^{R T}}$ :the $j$ th industry of Taiwan (T) uses the $i$ th's import products or service of other countries (R) (except Cross-Strait) as intermediate input

$Z_{i j}^{M^{R C}}$ :the $j$ th industry of Mainland China (C) uses the $i$ th's import products or service of other countries(R) (except Cross-Strait) as intermediate input

$F_{i}^{D^{T T}}$ :the $j$ th industry of Taiwan (T) uses the $i$ th's domestic products or service of Taiwan (T) as domestic final demand

$F_{i}^{M^{T C}}$ :the $j$ th industry of Mainland China $(\mathrm{C})$ uses the $i$ th's import products or service of Taiwan $(\mathrm{T})$ as domestic final demand

$F_{i}^{D^{C C}}$ :the $j$ th industry of Mainland China (C) uses the $i$ th's domestic products or service of Mainland China (C) as domestic final demand

$F_{i}^{M^{C T}}$ :the $j$ th industry of Taiwan (T) uses the $i$ th's import products or service of Mainland China $(\mathrm{C})$ as domestic final demand

$F_{i}^{M^{R T}}$ :The $j$ th industry of Taiwan (T) uses the $i$ th's import products or service of other countries (R) (except Cross-Strait) as domestic final demand

$F_{i}^{M^{R C}}$ :The jth industry of Mainland China (C) uses the ith's import products or service of other countries (R) (except Cross-Strait) as domestic final demand

$E_{i}^{T C}:$ The $i$ th industry products or service of Taiwan (T) export to Mainland China (C)

$E_{i}^{T R}$ the $i$ th industry products or service of Taiwan (T) export to other countries (R)

$E_{i}^{C T}$ :the $i$ th industry products or service of Mainland China (C) export to Taiwan (T)

$E_{i}^{C R}$ :the $i$ th industry products or service of Mainland China $(\mathrm{C})$ export to other countries (R) 
$X_{i}^{T}$ :the total output of Taiwan (T) $i$ th industry products or service

$X_{i}^{C}$ :the total output of Mainland China (C) $i$ th industry products or service

$M_{i}^{S_{1} C}$ :the $i$ th industry import products or service of Mainland China (C) $\left(\mathrm{S}_{1}\right.$ :from Taiwan (T), from other countries (R)

$M_{i}^{S_{2} T}$ :the $i$ th industry import products or service Taiwan $(\mathrm{T})\left(\mathrm{S}_{1}\right.$ :from Mainland China $(\mathrm{C})$, from other countries $(\mathrm{R})$

$F I_{j}^{Z T}$ :the international shipping fee and assurance of Taiwan $(\mathrm{T}) j$ th industry use import products as intermediate input

$F I_{j}^{Z C}$ :the international shipping fee and assurance of Mainland China $(\mathrm{C}) j$ th industry use import products as intermediate input

$F I_{j}^{F T}$ :the international shipping fee and assurance of Taiwan (T) $j$ th industry use import products as domestic final demand

$F I_{j}^{F C}$ :The international shipping fee and assurance of Mainland China $(\mathrm{C}) j$ th industry use import products as domestic final demand

$A_{j}^{Z T}$ :the adjustment of Taiwan (T) $j$ th industry use as intermediate input

$A_{j}^{Z C}$ :the adjustment of Mainland China (C) jth industry use as intermediate input

$A_{j}^{F T}$ :the adjustment of Taiwan (T) $j$ th industry use as domestic final demand

$A_{j}^{F C}$ :the adjustment of Mainland China (C) $j$ th industry use as domestic final demand

$V_{j}^{T}$ :the primary input of Taiwan (T) $j$ th industry

$V_{j}^{C}$ :the primary input of Mainland China (C) jth industry

$X_{j}^{T}$ :the total input of Taiwan (T) $j$ th industry

$X_{j}^{C}$ :the total input of Mainland China (C) $j_{-}$th industry

\section{The methods and steps of compiling explanation of 96 sectors Cross-Strait ICIO table}

The source of Taiwan-Mainland China ICIO table came from 166 sectors Taiwan Input Output table in 2006 compiling by Directorate-General Budget, Accounting and Statistics (DGBAS), Executive Yuan of Taiwan, and 135 sectors Mainland China Input Output table in 2007 compiling by National Bureau of Statistics of Mainland China.

\section{Integrating the classification sectors of Taiwan and Mainland China Input Output tables}

The classification sectors of Taiwan Input Output table in 2006 and Mainland China Input Output table in 2007 are not the same. The author integrated the classification sectors of 166 sectors in Taiwan and 135 sectors in Mainland China Input Output table to 96 sectors (see Table 7)

\section{Estimating Mainland China domestic and import Input Output tables}

There are 166 sectors' Taiwan domestic and import Input Output tables in 2006 compiling by DGBAS of Taiwan. In Mainland China, there is only an Input Output table at producers' prices in 2007. Therefore, the author applied the assumption of all industries using the assumption of import rate of domestic demand (including output and net import) which is equal to estimate the 135 sectors of Mainland China domestic and import Input Output tables in 2007.

\section{Adjustment the base of pricing}

Choose 2006 as the benchmark year. Then, calculate the output, import, salary, and depreciation price deflators to deflate the 96 sectors in Mainland China Input Output table from 2006 to 2007. It means 2006 is the benchmark year. The next 
step is applying the exchange rate to adjust the RMB to NT pricing.

\section{Using source and usage of Cross-Strait trade data to estimate the ICIO table}

Finally, use the source of Cross-Strait export and import statistic data to separate the trade data in original Input Output table. Then, use the trade data to estimate the intermediate and final demand of ICIO table. Then, adjust the balance of CrossStrait ICIO table between supply and demand sides.

\section{The fragment and formulas of 96 sectors Cross-Strait ICIO table}

Following the above steps could finish compiling 96 sectors Cross-Strait ICIO table in 2006. The fragment and relationship of vectors and matrixes in Cross-Strait ICIO table can be seen in Table 8.

Open Access This article is distributed under the terms of the Creative Commons Attribution 4.0 International License (http:// creativecommons.org/licenses/by/4.0/), which permits unrestricted use, distribution, and reproduction in any medium, provided you give appropriate credit to the original author(s) and the source, provide a link to the Creative Commons license, and indicate if changes were made.

\section{References}

Ahmed A, Masud MM, Al-Amin AQ, Yahaya SRB, Rahman M, Akhtar R (2015) Exploring factors influencing farmers' willingness to pay (WTP) for a planned adaptation programme to address climatic issues in agricultural sectors. Environ Sci Pollut Res 22:9494-9504

Myles AE, Allen AJ, Saleem S, 2005. "An inter-sector impact of hurricanes Katrina and Rita on the agribusiness industry in Mississippi," Selected Paper prepared for presentation at the Southern Agricultural Economics Association Annual Meeting, Mobile, Alabama, February 1-5.

Chang HH, Zilberman D (2014) On the political economy of allocation of agricultural disaster relief payments: application to Taiwan. Eur Rev Agric Econ 41:657-680

Charlotte, B. 2003. "Potential Approaches to the Development of Indicators for Measuring Risk from a Macroeconomic Perspective, "Information and Indicators Program for Disaster Risk Management-Indicators for Disaster Risk Management, InterAmerican Development Bank, Operation ATN/JF-7907-RG.

Claassen R, Cooper JC, Carriazo F (2011) Crop insurance, disaster payments, and land use change: the effect of sodsaver on incentives for grassland conversion. J Agric Appl Econ 43:195-211

Clower, T. L., 2005. "Economic Applications in Disaster Research, Mitigation, and Planning,"From http://training.fema.gov/EMIWeb/ edu/docs/Disciplines\%20Disasters\%20and\%20EM\%20Book\% 20-\%20Chapter-Econ\%20appli\%20in\%20disasters\%20research. doc Directorate-General of Budget, Accounting and Statistics, Executive Yuan, R.O.C, 2009. 2006 Taiwan Input Output table.

Fischer G, Mahendra S, Harrij V (2002) Climate Change and Agricultural Vulnerability. International Institute for Applied Systems Analysis, Viena

Furen JIANG, Hirokazu TATANO, Yasuhisa KUZUHA, Tomonori MATSUURA (2005) Economic Loss Estimation of Water Supply
Shortage Based on Questionnaire Survey in Industrial Sectors. Disaster Prevention Research Group, National Research Institute for Earth Science and Disaster Prevention (NIED), Japan

Garrett TA, Marsh TL, Marshall MI (2006) Political allocation of US Agriculture Disaster Payments in the 1990s. Int Rev Law Econ 26: 143-161

Goodwin BK, Vado LA (2007) Public responses to agricultural disasters: rethinking the role of government. Can J Agric Econ 55:399-417

Goodwin BK, Rejesus RM (2008) Safety nets or trampolines? Federal crop insurance, disaster assistance, and the farm bill. J Agric Appl Econ 40:415-429

Gordon P, Moore JE, Richardson HW, Shinozuka M, An D, Cho S 2004. Earthquake disaster mitigation for urban transportation systems: anintegrated methodology that builds on the Kobe and Northridge experiences, In: Okuyama Y, Chang SE (eds) Modeling Spatial and Economic Impacts of Disasters. Advances in Spatial Science. Springer, Berlin, Heidelberg

Gordon P, Richardson HW, Davis B (1998) transport-related impacts of the Northridge earthquake. J Transp Stat 1:21-36

Krosnick JA, Holbrook AL, Lowe L, Visser PS (2006) The origins and consequences of democratic citizens' policy agendas: a study of popular concern about global warming. Climate Change 77:7-43

Leiserowitz A (2006) Climate change risk perception and policy preferences: the role of affect, imagery, and values. Climate Change 77:45-72

Lin HC (2013) The Taiwan's economic impact of Cross-Strait agricultural trade: Regional Input-Output Analysis. Taiwanese Agri Econ Rev 19: $81-127$

Lin HC, Kao TM, Chou LC, Chang CC, 2010. The Economic Impact from Agricultural Products Loss Caused by Natural Disasters and Regional Input-Output Analysis in Taiwan, selected paper presented at The 1st Congress of East Asian Association of Environmental and Natural Resource Economics, Hokkaido University, Sapporo, Japan.

Lorenzoni I, Pidgeon NF (2006) Public views on climate change: European and USA perspectives. Climate Change 77:73-95

Mary WD, Pielke RA (2005) How accurate are disaster loss data? The case of U.S. flood damage. Nat Hazards 35:211-228

Masud MM, Akhatr R, Nasrin S, Adamu IM (2017) Impact of sociodemographic factors on the mitigating actions for climate change: a path analysis with mediating effects of attitudinal variables. Environ Sci Pollut Res 24:26462-26477

McElhinney J (2016) Influencing the agricultural sector to embrace adaptation to climate change, for the sake of global food security. Environ Sci Pollut Res 23:9245-9246

Miller RE, Blair PD (2009) Input-Output Analysis : Foundations and Extensions, Second edn. Cambridge University Press, London

Okuyama Y (2007) Economic modeling for disaster impact analysis past present and future. Econ Syst Res 19:115-124

Rose A, Benavides J, Chang S, Szczesniak P, Lim D (1997) The regional economic impact of an earthquake:direct and indirect effects of electricity lifeline disruptions. $J$ Reg Sci 37:437-458

Rose A, Liao S (2005) Modeling resilience to disasters:computable general equilibrium analysis of a water service disruption. J Reg Sci 45(1):75-112

Shi T (2009) Crisis and response: natural disasters and T'ang Society. China Agri Econ Rev 1(4):485-488

Tsuchiya S, Hirojazu T, Norio O (2007) Economic loss assessment due to railroad and highway disruptions. Econ Syst Res 19:147-162

Wang J, Huang J, Yang J (2014) Overview of impacts of climate change and adaptation in China's agriculture. J Integr Agric 13:1-17

Yamano N, Yoshio K, Yoshiharu H (2007) Modeling the regional economic loss of natural disasters the search for economic hotspots. Econ Syst Res 19:163-181

Zahran S, Brody SD, Grover H, Vedlitz A (2006) Climate change vulnerability and policy support. Soc Nat Resour 19:771-789

Publisher's note Springer Nature remains neutral with regard to jurisdictional claims in published maps and institutional affiliations. 